\title{
First-trimester maternal vitamin D status and risk for gestational diabetes (GDM) a nested case-control study
}

\author{
Arthur M. Baker ${ }^{1,}$, Sina Haeri ${ }^{2}$, Carlos A. Camargo Jr. ${ }^{3,4}$, Alison M. Stuebe ${ }^{5,6}$, and Kim A. \\ Boggess $^{5}$ \\ ${ }^{1}$ Memorial Health University, Medical Center, Mercer School of Medicine, Savannah Campus, \\ Savannah, GA \\ 2Division of Maternal-Fetal Medicine, Department of Obstetrics, and Gynecology, Baylor College \\ of Medicine, Houston, TX \\ ${ }^{3}$ Department of Emergency Medicine, Massachusetts General Hospital, Boston, MA \\ ${ }^{4}$ Center for D-receptor, Activation Research, Massachusetts General Hospital, Boston, MA \\ ${ }^{5}$ Division of Maternal-Fetal Medicine, Department of Obstetrics and Gynecology, University of \\ North Carolina, Chapel Hill, NC \\ ${ }^{6}$ Department of Maternal and Child Health, Gillings School of Global Public Health, University of \\ North Carolina, Chapel Hill, NC
}

\section{Abstract \\ Background-Vitamin D deficiency may contribute to impaired glucose metabolism. There are sparse data regarding vitamin D and the development of gestational diabetes (GDM). The objective of this study was to assess if first-trimester vitamin D deficiency is more prevalent in women later diagnosed with GDM compared with women with uncomplicated pregnancies.}

Methods-We conducted a nested case-control study of pregnant women who had previously given blood for routine genetic multiple marker screening and subsequently delivered at a tertiary hospital between November 2004 and July 2009. From an overall cohort of 4225 women, 60 cases of GDM were matched by race/ethnicity with 120 women delivering at term ( 37 weeks) with uncomplicated pregnancies. Banked maternal serum was used to measure maternal 25hydroxyvitamin D [25(OH)D].

Results-The prevalence of first-trimester maternal vitamin D deficiency (defined as 25(OH)D $<50 \mathrm{nmol} / \mathrm{L})$ was comparable among women with GDM compared with controls $(5 / 60 v s$ 8/120, $p$ $=0.90)$. The median $25(\mathrm{OH}) \mathrm{D}$ level for all subjects was $89 \mathrm{nmol} / \mathrm{L}$ (interquartile range, 73-106 nmol/L). Seventy three percent (117/160) of the cohort had 25(OH)D levels $\geq 75 \mathrm{nmol} / \mathrm{L}$.

Copyright (C) 2011 John Wiley \& Sons, Ltd.

"Correspondence to: Arthur M. Baker, Memorial Health, University Medical Center, Mercer School of Medicine, Savannah Campus 4750 Waters Avenue, Suite 302, Savannah, GA 31404, USA. arthurbaker@ memorialhealth.com.

Conflict of interest

The authors have no conflicts of interest to disclose. 
Conclusions-In a cohort of pregnant women with mostly sufficient levels of serum 25(OH)D, vitamin D deficiency was not associated with GDM. Further studies are warranted with larger cohorts, especially in populations with lower levels of vitamin D.

\section{Keywords}

gestational diabetes; pregnancy; vitamin D; 25-hydroxyvitamin D

\section{Introduction}

Gestational diabetes mellitus is glucose intolerance that first manifests itself in pregnancy. This common complication of pregnancy affects approximately $4 \%$ of all births in the United States [1]. As the prevalence of obesity continues to increase, the rate of gestational diabetes is also increasing [2-4]. Women that are diagnosed with GDM are at an increased risk of developing diabetes mellitus later in life. Moreover, women with gestational diabetes are more likely to deliver macrosomic infants, which confers a higher risk for shoulder dystocia and birth injuries such as nerve palsies and bone fractures [5]. In addition, the offspring of these mothers are more likely to be obese and glucose intolerant [6,7]. Evaluating pathophysiologic changes associated with GDM that are amenable to therapy could therefore impact both neonatal and maternal outcomes.

Recent evidence suggests that vitamin D deficiency may contribute to the development of type 2 diabetes mellitus [8,9]. Although the exact mechanism is unknown, this relationship may be related to the association of vitamin $\mathrm{D}$ deficiency and pancreatic $\beta$-cell dysfunction [10]. There are sparse data regarding vitamin D and the development of GDM. Researchers have previously reported lower maternal 25-hydroxyvitamin D [25 (OH)D] concentrations in women with GDM at the time of GDM-screening (24-29-week gestation) [11,12], and a single study has demonstrated lower levels at 16-weeks gestation before the diagnosis of GDM [13]. If these findings are replicated, vitamin D supplementation in deficient women may aid in the prevention of GDM. Consequently, our objective was to assess if firsttrimester vitamin D deficiency is more prevalent in women with GDM. We hypothesized that early pregnancy levels of vitamin D are lower among women who later develop GDM compared with healthy women who later deliver at term.

\section{Materials and methods}

\section{Study design}

We conducted a nested case-control study in a cohort of 4225 women. All women who had previously given blood for routine first-trimester genetic multiple marker screening and subsequently delivered at the University of North Carolina-Chapel Hill, between November 2004 and July 2009, were eligible. Nonfasting blood samples were collected for routine genetic multiple marker screening between 11 and 14-weeks gestation, and serum aliquots were barcoded and frozen at $-70{ }^{\circ} \mathrm{C}$. This study was approved by the Institutional Review Board at the University of North Carolina-Chapel Hill prior to data collection, and permission was obtained to use banked serum from these women for research purposes. 
Using a standard data collection sheet, two investigators (A. B. and S. H.) abstracted demographic characteristics, obstetrical and neonatal outcomes from prenatal and inpatient medical records. The following maternal characteristics were based on self-report: height, prepregnancy weight and date of last menstrual period. Gestational age was determined by menstrual dating. In cases of uncertain menstrual dates, ultrasound estimates of gestational age were used. Maternal body mass index (BMI) was calculated from the patient's selfreported height and prepregnancy weight. Other abstracted variables included race/ethnicity, maternal health insurance type and chronic maternal illness such as pregestational hypertension, diabetes, liver or kidney insufficiency or rheumatologic disorders.

Screening for GDM was most often performed between 24 and 28 weeks of gestation using a 50-gram glucose, 1-hour screening test. The threshold for obtaining a subsequent 3-hour 100 -gram oral glucose tolerance test was a serum glucose concentration of $140 \mathrm{mg} / \mathrm{dL}$. National Diabetes Data Group criteria were used to establish the diagnosis of GDM [14]. Early screening in the first or early second trimester was performed in patients considered high risk for gestational diabetes (i.e. prior affected pregnancy, strong family history of type 2 diabetes or BMI $\geq 30 \mathrm{~kg} / \mathrm{m}^{2}$ ). If these patients were screened negative, a repeat 50-gram, 1hour screening test was performed between 24 and 28 weeks of gestation. Exclusion criteria included pre-GDM, chronic hypertension, kidney disease, known thrombophilias, multiple gestation, major congenital fetal anomalies or any other significant preexisting chronic medical disease.

From the total cohort of 4225 women, 124 women were diagnosed with GDM, and 60 had met all inclusion and exclusion criteria listed above. All 60 cases had an adequate volume of serum available for analysis. These cases were matched by race/ethnicity, in 2: 1 ratio, to a random computer-generated referent group of 120 healthy women delivering at term ( $>37$ weeks) using the same exclusion criteria. Assuming a 25\% rate of vitamin D deficiency in the control group, an absolute increase in vitamin D deficiency of $25 \%$ in the case group (50\%) and $\alpha$ of 0.05 , we needed a sample size of at least 171 patients (cases: 57 , controls: 114 ) to achieve $90 \%$ power.

\section{Laboratory analyses}

Serum aliquots of cases and controls were shipped on dry ice to Massachusetts General Hospital (MGH, Boston, MA) for serum 25(OH)D measurement by liquid chromatographytandem mass spectrometry [15]. The method used is an isotope dilution, liquid chromatography-mass spectrometry assay optimized in MGH laboratory based on published procedures [16]. The limit of detection is $5 \mathrm{nmol} / \mathrm{L}$ for $\mathrm{D} 2$ and $7.5 \mathrm{nmol} / \mathrm{L}$ for $\mathrm{D} 3$. Values that were outside the limits of detection were excluded from the analysis. The between-run coefficient of variation for a quality control serum containing a total vitamin D concentration of $57 \mathrm{nmol} / \mathrm{L}$ is $7.5 \%$. On the basis of the definitions of vitamin D status in the literature [17,18], we categorized 25(OH)D $\geq 75 \mathrm{nmol} / \mathrm{L}$ as sufficient and $25(\mathrm{OH}) \mathrm{D}$ 50-74.9 $\mathrm{nmol} / \mathrm{L}$ as insufficient. Vitamin D deficiency was defined as $25(\mathrm{OH}) \mathrm{D}<50 \mathrm{nmol} / \mathrm{L}$. 


\section{Statistical analysis}

We performed unadjusted analyses using Wilcoxon-Mann-Whitney and Fisher's exact tests to compare differences between cases and controls. Multivariable logistical regression was performed to evaluate independent predictors of GDM with results reported as odds ratios (ORs) with 95\% confidence intervals (CIs). Data were analyzed using IBM SPSS Statistics software (version 19.0, SPSS, Inc., Chicago, IL) and were summarized using descriptive statistics. All $p$ values were two-tailed, with $p<0.05$ considered statistically significant.

\section{Results}

We successfully analyzed $25(\mathrm{OH}) \mathrm{D}$ levels from all 180 samples (60 cases; 120 controls). The median gestational age of serum collection was similar for the two groups (13 weeks). As shown in Table 1, women with gestational diabetes had a significantly higher BMI (29 vs 25, $p=0.003$ ) and were delivered on average 1 week earlier than controls (38 vs 39 weeks, $p$ $<0.001)$. All other demographic and clinical characteristics between the groups in early pregnancy were similar. The median $25(\mathrm{OH}) \mathrm{D}$ level for all subjects was $89 \mathrm{nmol} / \mathrm{L}$ (interquartile range, $73-106 \mathrm{nmol} / \mathrm{L})$. Seventy three percent (132/180) of the cohort had $25(\mathrm{OH}) \mathrm{D}$ levels $\geq 75 \mathrm{nmol} / \mathrm{L}$. There was a small negative correlation $(s=-0.1)$ between BMI and 25(OH)D. There was a trend toward higher concentration of 25(OH)D in fall and summer and lower 25(OH)D in the winter months.

The prevalence of first-trimester maternal $25(\mathrm{OH}) \mathrm{D}$ deficiency $(<50 \mathrm{nmol} / \mathrm{L})$ was similarly low among women later diagnosed with GDM and healthy controls $(8.3 \%$ vs $6.7 \%$, respectively; $p=0.90)$. In unadjusted models, first-trimester maternal $25(\mathrm{OH}) \mathrm{D}<50 \mathrm{nmol} / \mathrm{L}$ was not associated with gestational diabetes (OR 1.25; 95\% CI, 0.39-4.05) compared with first trimester levels of $\geq 75 \mathrm{nmol} / \mathrm{L}$ (Table 2). We similarly found no association between $25(\mathrm{OH}) \mathrm{D}<50 \mathrm{nmol} / \mathrm{L} v s \geq 75 \mathrm{nmol} / \mathrm{L}$ and gestational diabetes after adjustment for maternal age, insurance status, BMI, gestational age at serum collection and season of blood draw (adjusted OR, 0.78; 95\% CI, 0.22-2.78). We also examined the mean 25(OH)D between the groups. While mean 25(OH)D was higher among cases $(97 \pm 29$ vs $86 \pm 22 \mathrm{nmol} / \mathrm{L}, p=$ $0.02)$, this effect was attenuated by maternal BMI and season of blood draw $(p=0.24)$.

\section{Discussion}

In this study, we measured the association between first-trimester vitamin D deficiency and GDM. We found no difference in the prevalence of early pregnancy vitamin D deficiency (defined as $25(\mathrm{OH}) \mathrm{D}<50 \mathrm{nmol} / \mathrm{L}$ ) between women with gestational diabetes compared with women with uncomplicated pregnancies delivering at term. However, the overall prevalence of vitamin D deficiency in our study cohort was only $7.2 \%$, with only 13 of 180 women in this category. This is much lower than the recently published data reporting a 33\% rate of vitamin D deficiency in a nationally representative sample of pregnant women in the United States [19].

There are few studies on vitamin D status in pregnancy and its association with gestational diabetes, and all of these studies reported much higher rates of vitamin D deficiency than we found in our cohort. Maghbooli et al. examined maternal serum 25(OH)D deficiency and 
gestational diabetes in a cross-sectional study of 741 pregnant women at 24-28-weeks gestation. They reported significantly lower levels of $25(\mathrm{OH}) \mathrm{D}$ in women with gestational diabetes compared to euglycemic controls. In contrast to our study, the rate of severe vitamin D deficiency $(<25 \mathrm{nmol} / \mathrm{L})$ in the Maghbooli cohort was high at $71 \%$ [11]. CliftonBligh et al. reported that maternal serum 25(OH)D concentrations at the time of glucose tolerance screening (29-weeks gestation) was significantly and inversely associated with fasting glucose. In their cohort of 307 women, $48 \%$ had a serum $25(\mathrm{OH}) \mathrm{D}<50 \mathrm{nmol} / \mathrm{L}$ [12]. In the only other study evaluating early pregnancy (16-weeks gestation) vitamin D deficiency and gestational diabetes, Zhang et al. noted a 2.66-fold increased risk of gestational diabetes in women with vitamin D deficiency. The rate of vitamin D deficiency $(<50 \mathrm{nmol} / \mathrm{L})$ in the Zhang study was also high at $20 \%$ [13].

Our findings must be interpreted in the context of the study design. A surprisingly high number of women in our cohort had sufficient vitamin D status. There are several possible explanations for this finding. Perhaps the most significant factor is that the majority of the patients in this study were privately insured (88\%) and thus more likely to be taking nutritional supplements and be physically active [20]. Unfortunately, we do not have information regarding supplement use or exposure to sunlight in this study. The geographical location of the study (North Carolina) also could have played a role via unmeasured lifestyle differences (i.e. amount of time spent outside). In addition, we were unable to determine an optimal cutpoint for GDM, given our small sample size and small number of women with $25(\mathrm{OH}) \mathrm{D}<75 \mathrm{nmol} / \mathrm{L}$. Although there is not uniform agreement as to 'optimal' vitamin D status, the vitamin D levels necessary to prevent rickets are much lower than levels that have been associated with non-bone-related outcomes [21]. Recent evidence suggests that vitamin D deficiency may be associated with cancer, cardiovascular disease, autoimmune disease and many other adverse health outcomes [22]. For examples, $25(\mathrm{OH}) \mathrm{D}<75 \mathrm{nmol} / \mathrm{L}$ is associated with periodontal disease [23], and levels $<50 \mathrm{nmol} / \mathrm{L}$ are associated with severe pre-eclampsia [24]. Moreover, our study population also may not be generalizable to all pregnant women. The prevalence of vitamin D deficiency in pregnancy is highest among African American (black) women [25]. Our study population was more than $50 \%$ white, which limits extrapolation to ethnically diverse groups.

Selection bias is also a concern in any case-control study, especially in the selection of controls. It is challenging to control for all potential covariates, and it is possible that unmeasured differences exist between the two study groups. However, our controls were nested within a large cohort of women who provided serum samples as part of routine prenatal screening, reducing selection bias. An important strength of our study is that maternal serum was collected well before the diagnosis of GDM, reducing the likelihood that subclinical disease affected vitamin D levels. However, it is possible that some women may have had prepregnancy glucose intolerance that was undiagnosed at the time blood draw.

In conclusion, in a cohort of women with a median serum $25(\mathrm{OH}) \mathrm{D}$ of $89 \mathrm{nmol} / \mathrm{L}$, vitamin D status was not associated with GDM. Future studies in high risk, racially diverse and low income populations are needed to determine the association of vitamin D status and GDM. 


\section{Acknowledgments}

This research was supported, in part, by the Bowes/Cefalo Young Researcher Award (AMB) and the Massachusetts General Hospital Center for D-receptor Activation Research (CAC). The resources of the BHRC research network are gratefully acknowledged (A. M. B. and S. H.).

\section{References}

1. American Diabetes Association. Diagnosis and classification of diabetes mellitus. Diabetes Care. 2008; 31(Suppl 1):S55-S60. [PubMed: 18165338]

2. Kim C, Newton KM, Kopp RH. Gestational diabetes and the incidence of type 2 diabetes: a systematic review. Diabetes Care. 2002; 25:1862-1868. [PubMed: 12351492]

3. King H, Aubert RE, Herman WH. Global burden of diabetes, 1995-2025: prevalence, numerical estimates, and projections. Diabetes Care. 1998; 21:1414-1431. [PubMed: 9727886]

4. Dabelea D, Snell-Bergeou JK, Hartsfield CL, Bischoff KJ, Hamman RF, McDuffie RS. Increasing prevalence of gestational diabetes mellitus (GDM) over time and by birth cohort: Kaiser Permanente of Colorado GDM Screening Program. Diabetes Care. 2005; 28:579-584. [PubMed: 15735191]

5. Langer O, Yogev Y, Most O, Xenakis EM. Gestational diabetes: the consequences of not treating. Am J Obstet Gynecol. 2005; 192(4):989-997. [PubMed: 15846171]

6. Silverman BL, Metzger BE, Cho NH, Loeb CA. Impaired glucose tolerance in adolescent offspring of diabetic mother. Relationships to fetal hyperinsulinism. Diabetes Care. 1995; 18(5):611-617. [PubMed: 8585997]

7. Petitt DJ, Bennett PH, Knowler WC, Baird HR, Aleck KA. Gestational diabetes mellitus and impaired glucose tolerance during pregnancy. Long-term effects on obesity and glucose tolerance in the offspring. Diabetes. 1985; 34(Suppl 2):119-122. [PubMed: 3996763]

8. Forouhi NG, Luan J, Cooper A, Boucher BJ, Wareham NJ. Baseline serum 25-hydroxy vitamin D is predictive of future glycemic status and insulin resistance: the Medical Research Council Ely Prospective Study 1990-2000. Diabetes. 2008; 57(10):2619-2625. [PubMed: 18591391]

9. Kositsawat J, Freeman VL, Gerber BS, Geraci S. Association of A1C levels with vitamin D status in U.S. adults: data from the National Health and Nutrition Examination Survey. Diabetes Care. 2010; 33(6):1236-1238. [PubMed: 20215453]

10. Chiu KC, Chu A, Go VL, Saad MF. Hypovitaminosis D is associated with insulin resistance and beta cell dysfunction. Am J Clin Nutr. 2004; 79(5):820-825. [PubMed: 15113720]

11. Maghbooli Z, Hossein-Nezhad A, Karimi F, Shafaei AR, Larijani B. Correlation between vitamin D3 deficiency and insulin resistance in pregnancy. Diabetes Metab Res Rev. 2008; 24(1):27-32. [PubMed: 17607661]

12. Clifton-Bligh RJ, McElduff P, McElduff A. Maternal vitamin D deficiency, ethnicity and gestational diabetes. Diabet Med. 2008; 25(6):678-684. [PubMed: 18544105]

13. Zhang C, Qui C, Hu FB, et al. Maternal plasma 25-hydroxyvitamin D concentrations and the risk for gestational diabetes mellitus. PLoS One. 2008; 3(11):e3753. [PubMed: 19015731]

14. National Diabetes Data Group. Classification and diagnosis of diabetes mellitus and other categories of glucose intolerance. Diabetes. 1979; 28(12):1039-1057. [PubMed: 510803]

15. Roth HJ, Schmidt-Gayk H, Weber H, Niederau C. Accuracy and clinical implications of seven 25hydroxyvitamin D methods compared with liquid chromatography-tandem mass spectrometry as a reference. Ann Clin Biochem. 2008; 45:153-159. [PubMed: 18325178]

16. Singh RJ, Taylor RL, Reddy GS, Grebe SKG. C-3 epimers can account for a significant proportion of total circulating 25-hydroxyvitamin D in infants, complicating accurate measurement and interpretation of vitamin D status. J Clin Endocrinol Metab. 2006; 91:3055-3061. [PubMed: 16720650]

17. Holick MF. Vitamin D deficiency. N Engl J Med. 2007; 357(3):266-281. [PubMed: 17634462]

18. Canadian Paediatric Society. Vitamin D supplementation: recommendations for Canadian mothers and infants. Paediatr Child Health. 2007; 12(7):583-598. [PubMed: 19030432] 
19. Ginde AA, Sullivan AF, Mansbach JM, Camargo CA Jr. Vitamin D insufficiency in pregnant and nonpregnant women of childbearing age in the United States. Am J Obstet Gynecol. 2010; 202(5): 436.e1-436.e8. [PubMed: 20060512]

20. Kim J, Lee JS, Shin A, et al. Sociodemographic and lifestyle factors are associated with the use of dietary supplements in a Korean population. J Epidemiol. 2010; 20(3):197-203. [PubMed: 20410671]

21. Adams JS, Hewison M. Update in vitamin D. J Clin Endocrinol Metab. 2010; 95 (2):471-478. [PubMed: 20133466]

22. Souberbielle JC, Body JJ, Lappe JM, et al. Vitamin D and musculoskeletal health, cardiovascular disease, autoimmunity and cancer: recommendations for clinical practice. Autoimmun Rev. 2010; 9(11):709-715. [PubMed: 20601202]

23. Boggess KA, Espinola JA, Moss K, Beck J, Offenbacher S, Camargo CA. Vitamin D status and periodontal disease among pregnant women. J Periodontol. 2010 Sep 1. epub ahead of print. 10.1902/jop.2010.100384

24. Baker AM, Haeri S, Camargo CA Jr, Espinola JA, Stuebe AM. A nested case-control study of midgestation vitamin D deficiency and risk of severe preeclampsia. J Clin Endocrinol Metab. 2010; 95 (11):5105-5109. [PubMed: 20719829]

25. Bodnar LM, Simhan HN. Vitamin D may be a link to black-white disparities in adverse birth outcomes. Obstet Gynecol Surv. 2010; 65(4):273-284. [PubMed: 20403218] 
Table 1

Clinical and demographic characteristics of women who developed GDM and race/ethnicity-matched women who did not (controls)

\begin{tabular}{|c|c|c|c|}
\hline Variables & Controls $(n=120)$ & $\operatorname{GDM}(n=60)$ & $p$ \\
\hline Age (years) ${ }^{a}$ & $33(30-36)$ & $35(31-37)$ & 0.11 \\
\hline Race/ethnicity, $n(\%)$ & & & - \\
\hline White & $63(52)$ & $31(52)$ & \\
\hline Black & $39(33)$ & $20(33)$ & \\
\hline Hispanic & $12(10)$ & $6(10)$ & \\
\hline Other & $6(5)$ & $3(5)$ & \\
\hline Multiparous, $n(\%)$ & $64(53)$ & $39(65)$ & 0.15 \\
\hline Private insurance, $n(\%)$ & $105(88)$ & $53(88)$ & 0.99 \\
\hline Body mass index ${ }^{a}$ & $25(22-28)$ & $29(26-34)$ & 0.003 \\
\hline Gestational age at serum collection (weeks) ${ }^{a}$ & $13(12-13)$ & $13(12-13)$ & 0.41 \\
\hline Gestational age at delivery (weeks) $^{a}$ & $39(39-40)$ & $38(37-39)$ & $<0.001$ \\
\hline Season of blood draw, $n(\%)$ & & & 0.002 \\
\hline Winter & $36(30)$ & $15(25)$ & \\
\hline Spring & $26(22)$ & $18(30)$ & \\
\hline Summer & $28(23)$ & $13(22)$ & \\
\hline Fall & $30(25)$ & $14(23)$ & \\
\hline Serum 25(OH)D level, $n(\%)$ & & & 0.95 \\
\hline$<50 \mathrm{nmol} / \mathrm{L}$ & $8(6.7)$ & $5(8.3)$ & \\
\hline $50-74.9 \mathrm{nmol} / \mathrm{L}$ & $24(20)$ & $11(18.3)$ & \\
\hline $75+\mathrm{nmol} / \mathrm{L}$ & $88(73.3)$ & $44(73.3)$ & \\
\hline
\end{tabular}

25(OH)D, 25-hydroxyvitamin D.

${ }^{a}$ Values are median (interquartile range).

Wilcoxon-Mann-Whitney test for continuous variables; Fisher's exact test for categorical variables. 


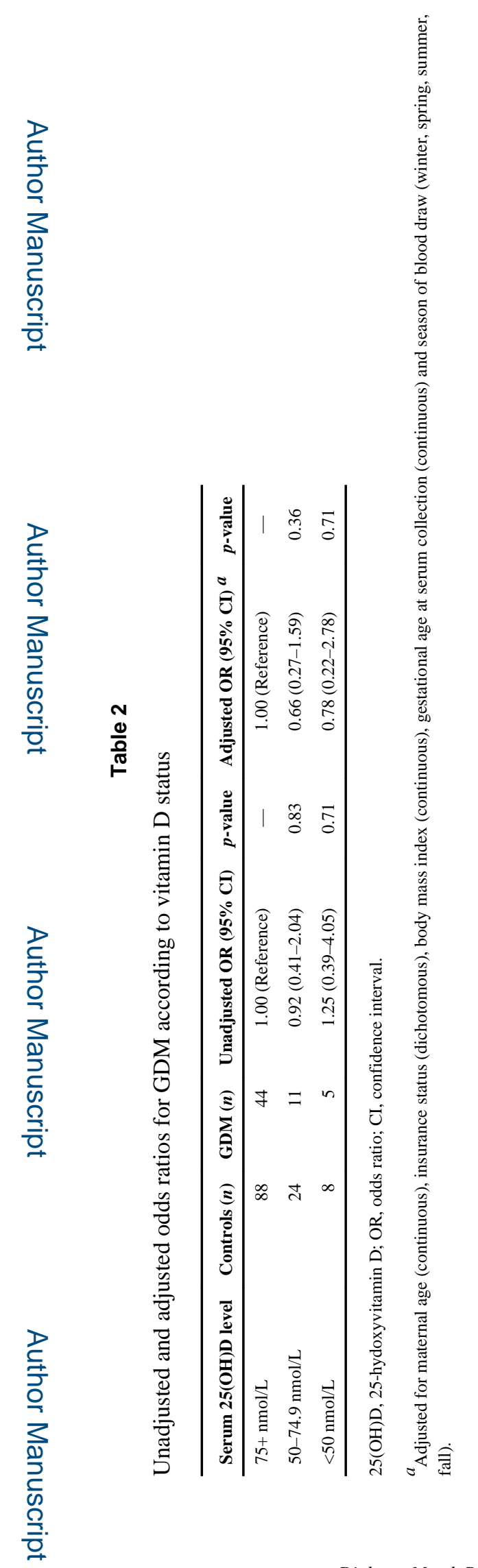

Diabetes Metab Res Rev. Author manuscript; available in PMC 2015 April 01. 